\title{
Infant Development as Uncertainty Reduction: Bayesian Insights on Phonological Acquisition
}

\author{
Christopher Martin Mikkelsen Cox ${ }^{1,2,3}$ (ccox@cc.au.dk) \\ Riccardo Fusaroli 1,2 (fusaroli@cas.au.dk) \\ Tamar Keren-Portnoy ${ }^{3}$ (tamar.keren-portnoy@york.ac.uk) \\ Andreas Roepstorff ${ }^{1,2}$ (andreas.roepstorff@cas.au.dk)
}

December 2020

\footnotetext{
${ }^{1}$ School of Communication and Culture, Aarhus University Jens Chr. Skous Vej 2, Building 1485, 8200 Aarhus, Denmark

${ }^{2}$ Interacting Minds Centre, Aarhus University Jens Chr. Skous Vej 4, Building 1483, 8200 Aarhus, Denmark

${ }^{3}$ Department of Language and Linguistic Science, University of York Vanbrugh College, Heslington, York YO10 5 DD, United Kingdom
}

Word Count: 9010 words

Correspondence: chris.mm.gmail.com (Chris Cox) 


\section{Infant Development as Uncertainty Reduction: Bayesian Insights on Phonological Acquisition}

\subsection{Abstract}

Bayesian accounts of development posit that infants form predictions about the causes of sensory signals in their environment and select actions that resolve the largest amount of uncertainty. This paper considers how this approach to infant development can inform and unify insights from experimental research on early cognitive development and language acquisition. In order to establish whether infants' early inferential abilities conform to the basic assumptions of a Bayesian approach to cognition, we first conduct a systematic review of experimental studies on infants' ability to form predictions about probabilistic contingencies. These studies provide evidence that infants exhibit sensitivity to the probabilistic structure of their surrounding environment and recruit their own uncertainty to guide their exploration of information in the world. We then demonstrate how these Bayesian computational principles may apply in the context of language acquisition by conducting a second systematic review of experiments on the facilitative role of infants' vocal production. These studies indicate that infants are more likely to produce and allocate attention to those speech sounds that best afford the opportunity to reduce prediction error over time. This paper demonstrates how Bayesian models of cognition can offer a unifying framework to advance the understanding of cognitive processes in early development. This framework not only gives a larger perspective to current findings, but also provides conceptual tools to enable investigation of infants' individual trajectories of behavioural change.

\section{0: Overview of Bayesian Models of Cognition: Infants Learn to Move \& Move to Learn}

This section provides an overview of the central properties of Bayesian models in order to clarify the theoretical concepts and terminology used throughout the paper. Bayesian models of cognition endorse an internalist construal of sensory processing, whereby 'top-down' expectations about the likely causes of sensory signals modulate the process of perception (Friston, 2005, 2010). Under this framework, learners work backwards from observed patterns of statistical dependencies to form predictions about the underlying processes that give rise to those patterns (Clark, 2013). Over the course of development, learners refine their predictive models by comparing the probabilistic predictions of multiple hypotheses about the state of the world and reducing mismatches between what is predicted and perceived (Hohwy, 2013; Kanai, Komura, Shipp, \& Friston, 2015). These probabilistic predictions operate across different spatiotemporal scales and levels of abstraction, 
from predictions about basic patterns in the physical world to the outcomes of specific actions and intentions (FeldmanHall \& Shenhav, 2019; Hohwy, 2013). The internal model of the learner can thus be construed as a statistical record of dynamic transactions between the organism and the environment (Friston, 2010).

When faced with a mismatch between a probabilistic prediction and a sensory input, learners can reduce the error signal in one of two ways: i) either by adjusting the higher-order structure of the probabilistic model, or ii) by performing actions to make the world align with model predictions (Feldman \& Friston, 2010; Friston, 2009). Empirical evidence for this form of dynamic adaptability can be found in Rovee-Collier's (1997) study of infants' responses to motoric contingencies. By connecting a mobile that moves in response to leg movements, 2-month-old infants were shown to produce higher leg kicking rates. When the mobile was thereafter disconnected, infants were shown to further increase their kicking rate. In Bayesian terms, these results indicate that infants identify their actions as the causes of contingent effects; the subsequent absence of the effect of infants' leg kicking produces a prediction error, which in turn, encourages infants to increase their leg kicking rate in order to adjust the world to their predictive models. Infants thus build increasingly accurate models of the world by minimising prediction errors over time, either by updating their predictive models or by using action to resolve uncertainty.

This process of prediction error minimisation depends on the relative precision of the prediction; that is, if learners expect a sensory input to be precise, then a mismatch between their expectations and sensory feedback will elicit a stronger prediction error signal (Friston, 2009). This process of precision estimation thus represents a second-order inferential process that assesses how much weight to assign to the incoming input (Hohwy, 2013). For example, a myopic person without any glasses on would rely more on the 'top-down' expectations of the location of different objects because the 'bottom-up' sensory input would be expected to be imprecise. This notion of precision likewise applies to action. If learners perform actions associated with high precision, then the absence of the expected outcome will produce a stronger prediction error signal than actions associated with low precision. If infants perform actions that reliably produce expected outcomes, such as the movement of a mobile in response to their leg kicking, then their confidence in these particular actions grows over time and elicits a stronger prediction error signal when an unexpected outcome occurs. Under a Bayesian framework, then, learners can weigh the confidence that should be placed in the discrepancy between a probabilistic prediction and a sensory input and use this weighted confidence to update their internal models of the world.

The Bayesian drive to minimise prediction errors over time may underlie infants' intrinsic curiosity and active exploration of the world (Stahl \& Feigenson, 2015; Twomey \& Westermann 
2018; Gopnik et al., 2017; Lucas, Bridgers, Griffiths, \& Gopnik, 2014). In addition to forming expectations about the causal processes that underlie their sensory experiences, infant learners are posited to form inferences about the extent to which particular actions will resolve uncertainty over the course of development (Feldman \& Friston, 2010; Friston, 2010). Kidd, Piantadosi, and Aslin (2012), for example, show that infants attend to visual stimuli according to the so-called 'Goldilocks principle'; participants allocate attention to visual stimuli that contain just the right amount of novelty to be maximally informative according their prior knowledge. This noveltyseeking behaviour forms a natural part of the way infants explore the world under a Bayesian framework.

In the following sections, we consider how this unifying perspective on cognition may advance our understanding of mechanistic commonalities in a variety of domains of infant development. We focus on early developmental stages because infants constantly face new behavioural challenges during this period and therefore have to adapt, update, and revise their skills. Such rapid developmental change lends itself well to being described in a Bayesian framework, as will be shown below. In the following section, we present a systematic review of experiments on infants' ability to form predictions about probabilistic contingencies. These studies indicate that young infants can form predictions about probabilistic events and that they use these predictions to guide their exploration of information in the world.

\section{0: A Systematic Review of Experimental Evidence on Infants' Ability to Form Predictions about Probabilistic Contingencies}

In order to obtain a comprehensive picture of the main insights and developments in the field, a literature search was conducted on PubMed and Web of Science. The search terms used were ("cognitive development" OR (infant) development OR (infant) cognition OR infancy) AND ("statistical inference" OR (probabilistic) reasoning OR (probabilistic) inference OR "causal learning" OR "probabilistic sampling"). These broad search terms were chosen in order to target experimental studies on infants' ability to form predictions about probabilistic contingencies and to provide a general characterisation of the extents and limits of this capacity. This search strategy yielded a total of 208 papers, which were screened for inclusion according to the following criteria: i) infants had to be typicallydeveloping, ii) aged between 0 and 24 months, and iii) the study had to involve an experimental component. Of the initial 208 papers, 38 were duplicates, 28 papers examined non-typical infant populations or infants outside the relevant age range, 60 papers did not have an experimental component, and 60 papers were unrelated to the topic under investigation. In order to trace the developmental trajectories of research questions and practices over time, we performed backward 
and forward literature searches on the basis of this initial search. In the backward literature search, we reviewed and identified relevant studies cited in the papers. In the forward literature search, we used Google Scholar to review and identify relevant references citing the papers. An overview of the included studies $(\mathrm{N}=22)$ is shown in Table 1 below.

Table 1: Included studies on infants' ability to form probabilistic predictions, where EEG = electroencephalography and VOE = violation of expectation. Age indicates months. Sample indicates sample size.

Study Topic
Age Sample

Paradigm

Main Findings

\begin{tabular}{|c|c|c|c|c|c|}
\hline Téglás et al. (2007) & $\begin{array}{l}\text { Predictions and intuitions } \\
\text { about uncertain events }\end{array}$ & 12 & 90 & VOE & $\begin{array}{l}12 \text { month-olds integrate probabilities in } \\
\text { their predictions of uncertain events. }\end{array}$ \\
\hline Xu \& Garcia (2008) & $\begin{array}{l}\text { Sample-to-population and } \\
\text { population-to-sample. }\end{array}$ & 8 & 100 & VOE & $\begin{array}{l}\text { Infants make statistical inferences in both } \\
\text { directions with small amounts of data. }\end{array}$ \\
\hline $\begin{array}{l}\text { Xu \& Denison } \\
(2009)\end{array}$ & $\begin{array}{l}\text { Sampling conditions and } \\
\text { intentional information }\end{array}$ & 11 & 72 & VOE & $\begin{array}{l}\text { Infants integrate sampling conditions and } \\
\text { intentional information in inference. }\end{array}$ \\
\hline $\begin{array}{l}\text { Denison \& Xu } \\
(2010 \mathrm{a})\end{array}$ & $\begin{array}{l}\text { Physical constraints \& } \\
\text { informative integration }\end{array}$ & 11 & 72 & VOE & $\begin{array}{l}\text { Infants override statistical information if } \\
\text { a physical constraint is more informative. }\end{array}$ \\
\hline $\begin{array}{l}\text { Denison \& Xu } \\
(2010 b)\end{array}$ & $\begin{array}{l}\text { Predictions about single-event } \\
\text { probability in large set sizes }\end{array}$ & $\begin{array}{l}12 \\
14\end{array}$ & 16,16 & $\begin{array}{l}\text { Forced-choice } \\
\text { paradigm }\end{array}$ & $\begin{array}{l}\text { Infants can reason about single-event } \\
\text { probabilities with large set sizes. }\end{array}$ \\
\hline Gweon et al. (2010) & $\begin{array}{l}\text { Inductive generalisation and } \\
\text { sampling strength }\end{array}$ & 15 & 130 & $\begin{array}{l}\text { Behavioural } \\
\text { observation }\end{array}$ & $\begin{array}{l}\text { Infants make inferences that are } \\
\text { consistent with strong sampling. }\end{array}$ \\
\hline Téglás et al. (2011) & $\begin{array}{l}\text { Pure reasoning and } \\
\text { probabilistic inference }\end{array}$ & 12 & 60 & VOE & $\begin{array}{l}\text { Infants form rational expectations when } \\
\text { faced with multiple information sources. }\end{array}$ \\
\hline $\begin{array}{l}\text { Denison, Reed \& } \\
\text { Xu (2012) }\end{array}$ & $\begin{array}{l}\text { Probabilistic reasoning in } \\
\text { young infants }\end{array}$ & $4.5,6$ & 16,16 & VOE & $\begin{array}{l}\text { 6-month-olds (and not 4.5-month-olds) } \\
\text { look longer at the improbable outcome. }\end{array}$ \\
\hline $\begin{array}{l}\text { Denison \& Xu } \\
(2014)\end{array}$ & $\begin{array}{l}\text { Infant sensitivity to } \\
\text { proportional distributions }\end{array}$ & 11 & 96 & $\begin{array}{l}\text { Forced-choice } \\
\text { paradigm }\end{array}$ & $\begin{array}{l}\text { Infants rely on the proportion of target } \\
\text { objects to reason under uncertainty. }\end{array}$ \\
\hline $\begin{array}{l}\text { Denison, Trikutam } \\
\& \mathrm{Xu}(2014)\end{array}$ & $\begin{array}{l}\text { Reasoning about physical } \\
\text { objects probabilistically }\end{array}$ & 11 & 60 & VOE & $\begin{array}{l}\text { Infants use physical constraints to } \\
\text { estimate probabilities. }\end{array}$ \\
\hline $\begin{array}{l}\text { Emberson et al. } \\
(2015)\end{array}$ & $\begin{array}{l}\text { Expectation-related feedback } \\
\text { and top-down modulation }\end{array}$ & 6 & 36 & $\begin{array}{l}\text { Functional near- } \\
\text { infrared spectroscopy }\end{array}$ & $\begin{array}{l}\text { Infants show activation consistent with } \\
\text { expectation-based feedback. }\end{array}$ \\
\hline Kouider et al. (2015) & $\begin{array}{l}\text { Neural responses to } \\
\text { prediction and surprise }\end{array}$ & 12 & 28 & EEG & $\begin{array}{l}\text { Neural responses to prediction violations } \\
\text { differ for (un)expected visual events. }\end{array}$ \\
\hline $\begin{array}{l}\text { Stahl \& Feigenson } \\
(2015)\end{array}$ & $\begin{array}{l}\text { Unexpectedness and } \\
\text { exploratory behaviour }\end{array}$ & 11 & 110 & VOE & $\begin{array}{l}\text { Objects violating expectations enhance } \\
\text { learning and promote exploration. }\end{array}$ \\
\hline
\end{tabular}




\begin{tabular}{|c|c|c|c|c|c|}
\hline Téglás et al. (2015) & $\begin{array}{l}\text { Numerical representations } \\
\text { and probabilistic inference }\end{array}$ & 12 & 70 & VOE & $\begin{array}{l}\text { Probability estimations are constrained by } \\
\text { limited numerical representations. }\end{array}$ \\
\hline $\begin{array}{l}\text { Wellman et al. } \\
\text { (2016) }\end{array}$ & $\begin{array}{l}\text { Probabilistic inference and } \\
\text { social understanding }\end{array}$ & 10 & 39 & VOE & $\begin{array}{l}\text { Infants infer intentional states of the } \\
\text { experimenter from statistical patterns. }\end{array}$ \\
\hline $\begin{array}{l}\text { Kayhan et al. } \\
\text { (2018) }\end{array}$ & $\begin{array}{l}\text { Sensitivity to likelihoods of } \\
\text { events }\end{array}$ & $\begin{array}{c}6,12 \\
18\end{array}$ & $\begin{array}{c}25,25 \\
25\end{array}$ & Eye-tracking & $\begin{array}{l}\text { Infants show sensitivity to likelihood according } \\
\text { to magnitude of difference. }\end{array}$ \\
\hline $\begin{array}{l}\text { Kayhan et al. } \\
\text { (2019) }\end{array}$ & $\begin{array}{l}\text { Updating of internal models } \\
\text { with changing environments }\end{array}$ & 13 & 29 & EEG & $\begin{array}{l}\text { Infants generate expectations and update their } \\
\text { internal models when necessary }\end{array}$ \\
\hline $\begin{array}{l}\text { Köster et al. } \\
(2019)\end{array}$ & $\begin{array}{l}\text { Neuronal dynamics of } \\
\text { unexpected events }\end{array}$ & 9 & 38 & EEG & $\begin{array}{l}\text { Visually-entrained theta oscillations showed an } \\
\text { increase for unexpected outcomes. }\end{array}$ \\
\hline Placì et al. (2019) & $\begin{array}{l}\text { Infant quantification of } \\
\text { probabilities as proportions }\end{array}$ & 12 & 34 & $\begin{array}{c}\text { Forced-choice } \\
\text { paradigm }\end{array}$ & $\begin{array}{l}\text { Infants do not rely on proportions of objects to } \\
\text { make probabilistic inferences. }\end{array}$ \\
\hline $\begin{array}{l}\text { Wu \& Gweon } \\
\text { (2019) }\end{array}$ & $\begin{array}{l}\text { Others' expression of surprise } \\
\text { and infant looking times }\end{array}$ & 15 & 28 & VOE & $\begin{array}{l}\text { Infants can use others' expression of surprise to } \\
\text { guide their understanding. }\end{array}$ \\
\hline $\begin{array}{l}\text { Attisano \& } \\
\text { Denison (2020) }\end{array}$ & Sampling intentionality & $6,9.5$ & 24,48 & VOE & $\begin{array}{l}\text { 6-month-olds expect intentional agents to } \\
\text { sample according to goals, not population. }\end{array}$ \\
\hline Kim et al. (2020) & $\begin{array}{l}\text { Informational uncertainty and } \\
\text { modulation of searching }\end{array}$ & 12,24 & 39,30 & $\begin{array}{l}\text { Behavioural } \\
\text { observation }\end{array}$ & $\begin{array}{l}\text { Infants delay search initiation according to } \\
\text { informational uncertainty. }\end{array}$ \\
\hline
\end{tabular}

\section{1: The Developmental Origins of Probabilistic Inference}

Some of the first experiments on probabilistic reasoning in early infancy investigate the extent to which infants can engage in tasks of probabilistic inference within their first year of life. Most of these experiments employ a violation-of-expectation paradigm, where infants' looking-time response functions as an indicator of the status of the sensory stimulus; that is, infants exhibit distinctive response patterns to outcomes that they find unexpected (i.e. events that violate their expectation). Téglás, Girotto, Gonzalez, and Bonatti (2007), for example, examine whether 12month-old infants can reason about probabilistic outcomes in the context of a single object being removed from a population of objects. The authors familiarise infants with a "lottery machine device" on a screen that displays four objects in a three-to-one, yellow-to-blue ratio. At test, the screen briefly conceals the "lottery machine device" before displaying one of two outcomes: either one of the yellow objects (the more-probable condition) or the blue object (the less-probable condition) disappears from the screen. The results demonstrate that infants on average look longer towards the screen in the less-probable condition, which indicates that 12-month-old infants consider a majority object to be a more likely outcome in a random draw from a group in a threeto-one ratio. 
$\mathrm{Xu}$ and Garcia (2008) extend these findings by using a violation-of-expectation paradigm and a live experimenter to test 8 -month-old infants' capacities to generalise about large populations from small samples. In test trials, the experimenter draws a total of five coloured ping-pong balls, one after another, from a covered box whose content remains unknown to the infant participants. Upon drawing balls from the covered box, the experimenter places them in a transparent container next to the covered box. For each trial, the experimenter draws either four red balls and one white ball (red-majority condition) or four white balls and one red ball (white-majority condition). After each of the five balls is drawn and subsequently placed in a transparent container, the experimenter opens the front panel of the covered box to reveal the contents to the infants. The contents of the covered box, however, are experimentally manipulated to display either predominantly red balls or predominantly white balls. If infants can assess the distributional properties of a population based on a small random sample, then the expectations of infants in the red-majority condition of sampling would be violated with the presentation of a box with predominantly white ping-pong balls, and vice versa. Infants exhibit significantly longer looking times in the conditions that produce unexpected outcomes, suggesting that infants can use a small random sample to assess what a population is likely to consist of. In a second experiment using the same experimental paradigm, Xu and Garcia (2008) test the reverse effect; that is, whether infants can make inferences from populations to samples. Infants exhibit significantly longer looking times in situations that showed a discrepancy between the distributional properties of the open box and the subsequent presentation of the sample. Téglás et al.'s (2007) and Xu and Garcia's (2008) findings suggest that infants can make powerful statistical inferences from small samples to large populations, and vice versa.

Denison, Reed, and Xu (2012), moreover, test whether this capacity to generalise from samples to populations is present in infants below the age of 8 months. The researchers test 4.5- and 6month-old infants with a similar experimental procedure to that of Téglás et al. (2007) and Xu and Garcia (2008), with a slightly different structure in order to reduce processing demands for the younger infants. The results demonstrate that 6-month-old infants exhibit longer looking times towards the less-probable condition of sampling four yellow balls and one pink ball from a box containing a majority of pink balls. In contrast, 4.5-month-old infants demonstrate similar looking times for both types of sampling. Although this may suggest that the capacity to reason from samples to populations comes online at around the age of 6 months, subsequent analyses of the infants' scanning behaviour in the experiment show that 4.5-month-old infants exhibit difficulties with their processing of relevant information in the experiment (i.e. the infants to a greater extent attend to the unsampled box during the experiment). Denison et al.'s (2012) study thus provides 
evidence that infants as young as 6 months of age are sensitive to probabilistic distributions and can make probabilistic inferences from samples to populations, but no clear conclusions can be drawn about 4.5-month-old infants' abilities.

The extent and limits of infants' inferential abilities were tested in subsequent experiments, showing that 11-month-old infants exhibit sensitivity to the randomness of sampling conditions (Xu \& Denison, 2009), that 11-month-olds integrate domain-specific knowledge to estimate probabilities (Denison \& Xu, 2010a, 2012), that 12-month-old infants are sensitive to spatiotemporal information in making probabilistic inferences (Téglás et al., 2011), that 14-monthold infants can update their internal models according to changes in the probabilistic structure of their environment (Kayhan, Hunnius, O'Reilly, \& Bekkering, 2019), and that 15-month-old infants use probabilistic data to make generalisations about object properties (Gweon, Tenenbaum, \& Schulz, 2010). These experiments provide evidence that infants make accurate probabilistic inferences about the structure of their ambient environment by integrating information from many different sources of information.

Denison and $\mathrm{Xu}$ (2014) investigate whether 12-month-old infants rely on proportional reasoning or frequency heuristics in making probabilistic inferences. This series of experiments teases apart notions of proportion and frequency by presenting infants with two populations; one of which has a higher proportion but a lower absolute number of target objects when compared to another population. The results suggest that infants use the proportional distributions of populations, instead of direct comparisons of absolute quantities, in making predictions about probabilistic outcomes. This study accords with Denison and Xu's (2010b) findings that 12- and 14-month-old infants can compute sampling probabilities in the context of large populations.

A recent study by Placì, Fischer, and Rakoczy (2019), however, calls Denison and Xu's (2010b, 2014) results into question. Placì et al. (2019) test 12-month-old infants and 36- and 48-month-old pre-schoolers in a near-identical experimental task to that of Denison and Xu's (2014) study. The authors find no evidence that infants and pre-schoolers rely on proportions in making probabilistic inference (Placì et al., 2019). These results are in line with Téglás, Ibanez-Lillo, Cosa, and Bonatti's (2015) finding that the effect of different looking times to expected and unexpected outcomes disappears when the quantity of objects in a visual scene is increased and the proportion of objects remains the same. Téglás et al. (2015) posit that 12-month-old infants rely on a process of quantifying and evaluating all the possible outcomes a random process can generate, which as a consequence, makes accurate probabilistic inference possible only when there is a small number of possible outcomes to track. The above contradictory results argue for more studies on the nature of infants' internal representations of probabilistic structure and the algorithms infants use 
to approximate the analytical solution (cf. Bonawitz, Denison, Griffiths, \& Gopnik, 2014). These future studies should also overcome some of the limitations of the above studies in that some of them only use one preference trial and fail to control for parental interference (e.g. Denison \& Xu, 2010b, 2014).

\section{2: Probabilistic Inference in Social Contexts}

The above studies provide robust evidence that infants can engage in probabilistic inference at a young age in response to situations where they make generalisations from samples to populations and vice versa. Recent studies employing similar violation-of-expectation methodologies investigate infants' abilities to infer the intentional states of others. Wellman, Kushnir, Xu and Brink (2016), for example, show that 10-month-old infants employ statistical information to infer the intentional state of the experimenter. Because intentional states, such as a preference for balls with a specific colour, can often result in unlikely sampling behaviours, a violation of random sampling conditions may function as a cue for infants to infer a hidden cause for the pattern. The looking time patterns in Wellman et al.'s (2016) experiment indicate that infants use the unlikelihood of sampling patterns to infer a causal intentional state (i.e. preferring a particular colour of ball). Attisano and Denison (2020) extend these findings by showing that infants as young as 6 months adjust their probabilistic expectations in contexts where the sampling behaviour of an experimenter produces samples that accord with his or her intentions. Infants' sensitivity to the unobservable social-psychological states of others, then, complements violations of expected probabilistic patterns in the world, suggesting mechanistic commonalities between probabilistic inference in various domains of learning during infancy. The relevance of infants' probabilistic inferences in social contexts receives further support from studies showing that infants recruit their own actions to understand others' goal-directed actions. For example, when infants aged 3 months wear 'sticky mittens' that facilitate their grasping experience, they exhibit increased sensitivity to the goal-directed behaviour of other social agents (Sommerville, Woodward, \& Needham, 2005). This close connection between action generation and prediction accords with Kanakogi and Itakura's (2011) findings that infants' ability to predict others' goal-directed grasping actions improves as infants themselves gain competence in performing such actions. These results highlight the relevance of dynamic reciprocity between the infant and other social agents in the environment over the course of development (Wu \& Gweon, 2019; de Bruin \& Michael, 2018; FeldmanHall \& Shenhav, 2019). 


\section{3: Sampling Conditions \& Intrinsic Curiosity}

Infants' adjustment of the precision of incoming probabilistic information according to sampling conditions and the intentions of social agents poses the question of the extent to which infants use this form of reasoning to forage for information in the world. Stahl and Feigenson (2015) show that 11-month-old infants to a greater extent explore and test hypotheses on objects that violate their prior expectations based on their core physics knowledge (e.g. a toy car that passes through a solid wall). This type of behaviour modulation according to the informational status of objects finds further support in Kim, Sodian and Proust's (2020) findings that the time delay of infants' search initiation for hidden objects depends on the informational uncertainty associated with that object. These studies indicate that infants are not only capable of learning and appreciating the statistical structure of their ambient environment, but that they use and flexibly adapt to this probabilistic information by modulating their exploratory strategies accordingly. This intrinsic motivation to explore novel objects, events and activities emerges naturally from a Bayesian approach to cognition under the assumption that agents seek to reduce entropy and minimise variational free energy over time (Friston, 2010).

\section{4: Note on Looking Time Measures}

Most of the studies reviewed so far employ a violation-of-expectation paradigm to investigate infants' inferential capacities. These behavioural responses receive a straightforward analysis within a Bayesian approach; because violations of prior expectations function as critical incidents for learning, infants' different looking time responses to expected versus unexpected outcomes may reflect the processing of prediction errors and adjustment of their predictive models. This Bayesian explanation for infants' looking time responses accords with studies on infants' neurophysiological responses to unexpected events. Emberson, Richards, and Aslin (2015), for example, use nearinfrared spectroscopy to provide evidence of trial-by-trial activation in 6-month-old infants' occipital cortex in response to unpredictable omissions of visual stimuli. Kouider et al. (2015) likewise present electro-encephalographic evidence to suggest that 12-month-old infants form predictions based on prior knowledge and that activation patterns depend on violations of these expectations. These studies and other recent studies (Kayhan, Hunnius, et al., 2019; Köster et al., 2019) provide evidence that infants form expectations based on prior knowledge and that violations of these predictions manifest in the brain electrophysiologically.

It should be noted, however, that because looking time measures by definition are an indirect measure of infants' knowledge, it can be difficult to rule out lower-level interpretations of their behavioural responses (Aslin, 2007); that is, it can be difficult to assess whether infants are simply 
making post-hoc judgements about probabilistic events or whether they form probabilistic predictions on a trial-to-trial basis. Future experiments may build on the methodology of Kayhan, Gredebäck, and Lindskog's (2018) eye-tracking study, showing that infants' looking patterns change uniformly as a function of the relative likelihood of probabilistic events. This type of scaling, where the dependent variable changes linearly in response to continuous changes in the stimulus properties, provides strong evidence that infant behaviour reflects the processes under investigation (Aslin, 2012).

\section{5: Interim Conclusion}

The above review of the studies in Table 1 suggests that the field is in broad agreement that infants employ statistical learning principles to form expectations about probabilistic contingencies and that they identify opportunities for learning based on prediction errors. These experimental results receive a straightforward analysis within a Bayesian approach to developmental cognition. Infants develop through a process of model revision and use their uncertainty to explore relevant information in the world. This analysis receives further support from neurophysiological evidence that violations of infants' prior expectations produce specific activation patterns in the brain. Further research on the extent to which infants rely on frequency-independent proportions to form predictions about probabilistic contingencies may be investigated by exploring the nature of the specific algorithms infants use to approximate Bayesian inference. In order to consider how these same general computational principles may apply in the context of language acquisition, the next section presents a systematic review of experiments on the facilitative influence of infants' vocal production in two subdomains of research: i) infants' auditory processing of the speech stream, and ii) their ability to perceive audio-visual congruence for speech sounds.

\section{0: A Systematic Review of Experiments on the Facilitative Influence of Infants' Speech}

\section{Production}

In order to obtain an overview of the main insights and developments in the field, a literature search was conducted on PubMed and Web of Science. The search terms used were ("speech production" OR production OR vocali* OR articulat*) AND ("speech perception" OR perception OR recepti*) AND ((infant) "language acquisition" OR (infant) "language development") AND (infant* OR child* OR toddler*). This search strategy yielded a total of 567 papers, which were screened for inclusion according to the following criteria: i) infants had to be typically-developing ii) aged between 0 and 24 months, and iii) the study had to involve an experimental component. Of the initial 567 papers, 52 were duplicates, 159 papers examined non-typical infant populations or infants outside the 
relevant age range, 39 papers did not have an experimental component, and 297 papers were unrelated to the topic under investigation. In order to trace the developmental trajectories of research questions and practices over time, we performed backward and forward literature searches on the basis of this initial search. In the backward literature search, we reviewed and identified relevant studies cited in the papers. In the forward literature search, we used Google Scholar to review and identify relevant references citing the papers. An overview of the included studies $(\mathrm{N}=20)$ is shown in Table 2 below.

Table 2: Overview of the included experimental studies on the facilitative effect of infants' speech production. The studies on rows 1-5 examine auditory-only speech perception, whereas studies on rows 6-20 investigate infants' ability to perceive multimodal congruence.
Study Topic
Age Sample Paradigm
Main Findings

\begin{tabular}{|c|c|c|c|c|c|}
\hline $\begin{array}{l}\text { DePaolis et al. } \\
\text { (2011) }\end{array}$ & $\begin{array}{l}\text { Infant production \& speech } \\
\text { processing }\end{array}$ & $9-11$ & 28 & $\begin{array}{l}\text { HT preference } \\
\text { procedure }\end{array}$ & $\begin{array}{l}\text { Infants show attentional shifts based on their } \\
\text { production patterns. }\end{array}$ \\
\hline $\begin{array}{l}\text { DePaolis et al. } \\
\text { (2013) }\end{array}$ & speech processing & $\begin{array}{c}10.5- \\
12\end{array}$ & 53 & $\begin{array}{l}\text { HT preference } \\
\text { procedure }\end{array}$ & $\begin{array}{l}\text { The attentional shift to novelty remains } \\
\text { independent of speech sound frequency. }\end{array}$ \\
\hline $\begin{array}{l}\text { Majorano et al. } \\
\text { (2014) }\end{array}$ & $\begin{array}{l}\text { Production experience \& } \\
\text { speech processing }\end{array}$ & 6 & 26 & $\begin{array}{l}\text { HT preference } \\
\text { procedure }\end{array}$ & $\begin{array}{l}\text { Replication of relation between infants' } \\
\text { speech production and attentional preference. }\end{array}$ \\
\hline $\begin{array}{l}\text { Bruderer et al. } \\
(2015)\end{array}$ & $\begin{array}{l}\text { Sensorimotor influences on } \\
\text { auditory speech perception }\end{array}$ & 6 & 72 & Cent & $\begin{array}{l}\text { Restraining articulators affects non-native } \\
\text { speech perception. }\end{array}$ \\
\hline Choi et al. (2019) & $\begin{array}{l}\text { Sensorimotor influences on } \\
\text { auditory speech perception }\end{array}$ & 6 & 96 & Central fixation & $\begin{array}{l}\text { Sensorimotor configurations influence native } \\
\text { and non-native speech perception. }\end{array}$ \\
\hline $\begin{array}{l}\text { Kuhl \& Meltzoff } \\
\text { (1982) }\end{array}$ & $\begin{array}{l}\text { Bimodality of speech } \\
\text { perception }\end{array}$ & 5 & 32 & $\begin{array}{l}\text { Audio-visual } \\
\text { matching task }\end{array}$ & $\begin{array}{l}\text { Infants can match auditorily and visually } \\
\text { presented speech sounds. }\end{array}$ \\
\hline $\begin{array}{l}\text { MacKain et al. } \\
\text { (1983) }\end{array}$ & Intermodal speech perception & 5.5 & 18 & $\begin{array}{l}\text { Audio-visual } \\
\text { matching task }\end{array}$ & $\begin{array}{l}\text { Infants recognise audio-visual } \\
\text { correspondences in disyllables. }\end{array}$ \\
\hline $\begin{array}{l}\text { Kuhl \& Meltzoff } \\
\text { (1984) }\end{array}$ & $\begin{array}{l}\text { Spectral information \& } \\
\text { speech perception }\end{array}$ & 5 & 64 & $\begin{array}{l}\text { Audio-visual } \\
\text { matching task }\end{array}$ & $\begin{array}{l}\text { Audio-visual matching depends on spectral } \\
\text { information of speech. }\end{array}$ \\
\hline Legerstee (1990) & Multimodal speech perception & 3.5 & 30 & $\begin{array}{l}\text { Audio-visual } \\
\text { matching task }\end{array}$ & $\begin{array}{l}\text { Infants imitate speech sounds using multi- } \\
\text { sensory information. }\end{array}$ \\
\hline $\begin{array}{l}\text { Kuhl \& Meltzoff } \\
(1996)\end{array}$ & $\begin{array}{l}\text { Vocal imitation \& speech } \\
\text { development }\end{array}$ & $3,4,5$ & $\begin{array}{c}24,24 \\
24\end{array}$ & $\begin{array}{l}\text { Audio-visual } \\
\text { matching task }\end{array}$ & $\begin{array}{l}\text { Infants produce vocalisations resembling } \\
\text { heard vowel sounds }\end{array}$ \\
\hline $\begin{array}{l}\text { Aldridge et al. } \\
\text { (1999) }\end{array}$ & $\begin{array}{l}\text { Intermodal speech perception } \\
\text { in neonates }\end{array}$ & 0 & 16 & $\begin{array}{l}\text { Audio-visual } \\
\text { matching task }\end{array}$ & $\begin{array}{l}\text { Neonates are sensitive to audio-visual } \\
\text { correspondences for speech. }\end{array}$ \\
\hline
\end{tabular}




\begin{tabular}{|c|c|c|c|c|c|}
\hline Study & Topic & Age & Sample & Paradigm & Main Findings \\
\hline $\begin{array}{l}\text { Patterson \& Werker } \\
\text { (1999) }\end{array}$ & $\begin{array}{l}\text { Intermodal speech } \\
\text { perception }\end{array}$ & 4.5 & 64 & $\begin{array}{l}\text { Audio-visual } \\
\text { matching task }\end{array}$ & $\begin{array}{l}\text { Infants link phonetic information } \\
\text { presented in the lips and voice. }\end{array}$ \\
\hline Pons et al. (2009) & $\begin{array}{l}\text { Intermodal perceptual } \\
\text { narrowing }\end{array}$ & $\begin{array}{c}6,6 \\
11,11\end{array}$ & $\begin{array}{l}24,24 \\
24,24\end{array}$ & $\begin{array}{l}\text { Audio-visual } \\
\text { matching task }\end{array}$ & $\begin{array}{l}\text { Infants become more sensitive to native } \\
\text { audio-visual matching over time. }\end{array}$ \\
\hline Coulon et al. (2013) & $\begin{array}{l}\text { Neonatal imitation of } \\
\text { vowels }\end{array}$ & 0 & 36 & $\begin{array}{l}\text { Audio-visual } \\
\text { matching task }\end{array}$ & $\begin{array}{l}\text { Neonates imitate more with audio-visually } \\
\text { congruent stimuli. }\end{array}$ \\
\hline Kubicek et al. (2013) & $\begin{array}{l}\text { Audio-visual matching of } \\
\text { (non-)native speech }\end{array}$ & 12 & 40 & $\begin{array}{l}\text { Audio-visual } \\
\text { matching task }\end{array}$ & $\begin{array}{l}12 \text { mo. infants do not perform cross- } \\
\text { modal matching for non-native speech. }\end{array}$ \\
\hline $\begin{array}{l}\text { Yeung \& Werker } \\
\text { (2013) }\end{array}$ & $\begin{array}{l}\text { Sensorimotor influences on } \\
\text { speech perception }\end{array}$ & 4.5 & 96 & $\begin{array}{l}\text { Audio-visual } \\
\text { matching task }\end{array}$ & $\begin{array}{l}\text { Articulator manipulations influence } \\
\text { infants' speech perception. }\end{array}$ \\
\hline $\begin{array}{l}\text { Lewkowicz et al. } \\
\text { (2015) }\end{array}$ & $\begin{array}{l}\text { Multimodal perception over } \\
\text { development }\end{array}$ & $\begin{array}{l}4,5-8 \\
12-14\end{array}$ & $\begin{array}{c}48,55 \\
48\end{array}$ & $\begin{array}{l}\text { Audio-visual } \\
\text { matching task }\end{array}$ & $\begin{array}{l}\text { Older infants perceive multisensory } \\
\text { coherence for native speech faster }\end{array}$ \\
\hline $\begin{array}{l}\text { Altvater-Mackensen } \\
\text { et al. (2016) }\end{array}$ & $\begin{array}{l}\text { Infant production \& audio- } \\
\text { visual perception }\end{array}$ & 6 & 44 & $\begin{array}{l}\text { Audio-visual } \\
\text { matching task }\end{array}$ & $\begin{array}{l}\text { Vowel type and production ability affect } \\
\text { audio-visual perception. }\end{array}$ \\
\hline Streri et al. (2016) & $\begin{array}{l}\text { Infant development of } \\
\text { audio-visual perception }\end{array}$ & $3,6,9$ & $\begin{array}{c}24,24 \\
24\end{array}$ & $\begin{array}{l}\text { Audio-visual } \\
\text { matching task }\end{array}$ & $\begin{array}{l}\text { The development of matching } \\
\text { performance depends on vowel category. }\end{array}$ \\
\hline Vilain et al. (2019) & $\begin{array}{l}\text { Production ability \& } \\
\text { consonant perception }\end{array}$ & 6,9 & 20,25 & $\begin{array}{l}\text { Audio-visual } \\
\text { matching task }\end{array}$ & $\begin{array}{l}\text { Babbling plays a role in the extraction of } \\
\text { consonants in speech. }\end{array}$ \\
\hline
\end{tabular}

\section{1: The Influence of Infants' Speech Production on their Speech Processing}

Despite widespread agreement of the significance of speech production in the process of language acquisition, experimental studies have only recently begun to explore the extent to which infants recruit sensorimotor knowledge in their auditory processing of the speech stream. One of the first experimental studies to consider the interplay between action and perception in the domain of phonological development explores the effect of infants' individual production experience on their attention to speech sounds in the speech stream. DePaolis, Vihman, and Keren-Portnoy (2011) recorded infants in half-hour play sessions around the onset of canonical babbling in order to track the emergence of stable patterns of articulatory activity in their speech production. Once infants showed evidence of producing stable patterns of coordinated articulatory activity, a so-called 'vocal motor scheme' (McCune \& Vihman, 2001), they were tested on their preference for short passages featuring nonwords. These passages either featured a specific vocal motor scheme (i.e. 'own VMS' condition) in the infant's production repertoire or a sound that was a vocal motor scheme for other infants of the same age (i.e. 'other VMS' condition). When compared with a control passage featuring a labiodental fricative, which infants are unlikely to use with any frequency at this age, the infants were shown to exhibit a differential response pattern to the stimuli depending on the number of vocal motor schemes in their repertoire. Infants with one vocal motor scheme exhibited 
longer looking times in the 'own-VMS' condition, whereas infants with more than one displayed longer looking times in the 'other VMS' condition. These results imply that infants' level of production practice of particular speech sounds can initiate shifts in how infants prefer to attend to aspects of the speech stream, from a preference for familiar speech sounds within their production repertoire to novel speech sounds outside of their production repertoire.

In order to explore whether this attentional shift remains independent of the frequency of consonants in the infants' linguistic input, DePaolis, Vihman, and Nakai (2013) employ a similar experimental paradigm to compare Welsh- and British English-learning infants' preference for lists of nonwords featuring consonants that occur with a similar frequency in the respective languages ([t] vs. [s] for English and [b] vs. [g] for Welsh). If infants' shift in attentional preference remains independent of the frequency of the respective consonants in the linguistic input, infants are expected to exhibit differential looking time responses to the two speech sounds, depending upon whether the speech sound forms part of their own production repertoire. The results showed that Welsh-learning infants producing $[\mathrm{b}]$ and $[\mathrm{g}]$ with comparable frequency in their babble exhibited similar looking times to the two sets of nonwords. The English-learning infants' attentional preference, on the other hand, was shown to exhibit an inverse relation to their relative production frequency of $[t / d]$; infants with a high proportion of $[t / d]$ production show longer looking times to the alveolar fricative [s], and vice versa. Because infants are unlikely to produce $[\mathrm{s}]$ at this age, this negative correlation provides further evidence that infants' familiarity with a particular speech sound in their own vocal production leads them to prefer to attend to speech sounds that do not yet form part of their own production repertoire. The attentional shift from familiarity to novelty based on infants' individual production repertoire has since been replicated with Italian-learning infants (Majorano, Vihman, \& DePaolis, 2014). This interplay between familiarity and novelty provides a means for infants to focus on a selected subset of the ambient language input, and in turn, guides infants to detect the speech sounds that are within and outside of their own production repertoire.

In Bayesian terms, the interplay between familiarity and novelty in the early stages of language acquisition may reflect infants' allocation of attention to speech sounds that afford the opportunity to reduce prediction error over time. As familiarity with both the production and perception of a specific speech sound accumulates over the course of development, the tendency for this speech sound to produce expected outcomes will become more reliable, and in turn, the amount of information an infant can derive from it will decrease. This development would render speech sounds outside infants' repertoire more attractive for infants to both attend to and produce, because these sounds now trigger stronger prediction error signals and thereby represent 
opportunities to gain new information. The Bayesian resolve to reduce prediction errors thus drives infants' intrinsic motivation to explore and provides a rational solution to the problem of deciding where to allocate attention in the world. This approach to developmental cognition captures the mutual interaction between infants' resolve to reduce their uncertainty about the world and their motor exploration of speech sounds.

The finding in the above studies that infants' level of speech production influences their auditory processing accords with Bruderer, Danielson, Kandhadai and Werker's (2015) investigation of English-learning infants' auditory discrimination of a non-native phonetic distinction: the contrast between the dental plosive, [d], vs. the retroflex plosive, [d]. These Hindi contrasts differ in the tongue tip placement required for their production; the former requires placement of the tongue tip behind the teeth, and the latter requires contact between the bottom side of the tongue tip and the roof of the mouth. By using teething toys to restrain infants' tongue tip placement, Bruderer et al. (2015) test infants' auditory discrimination of the phonetic contrast using a central fixation paradigm. The 6-month-old infants exhibit specificity in their discrimination of the phonetic contrast; a flat teething toy interfering with tongue-tip movement impedes infants' discrimination of the Hindi contrast, whereas a gummy teething toy interfering only with lip closure has no influence on their discrimination ability. These results provide evidence that infants incorporate sensorimotor knowledge into their representations of speech sounds and recruit this knowledge in processing speech, even when discriminating non-native speech sounds.

In a similar study, Choi, Bruderer, and Werker (2019) replicate these findings and extend the generalisability of the relation between infants' speech production and processing. Infants' discrimination of a familiar speech sound distinction was shown to be impeded by restricting movement of the relevant articulator; a teething toy preventing bilabial closure prevented discrimination between the bilabial [b] and dental [d]. As the researchers employ the same teething toy that did not interfere with discrimination of the [d] vs. [d] distinction in Bruderer et al. (2015) study, this provides robust evidence that impeding the specific oral-motor movements required for a speech sound disrupts infants' discrimination of that speech sound. These studies indicate an intimate interaction between sensorimotor and perceptual processes at an early point in language development.

\section{2: Infants' Speech Production \& Their Ability to Detect Audio-Visual Congruence}

Another line of research that examines the effect of infants' speech production on speech processing involves experimental studies of infants' ability to perceive audio-visual congruence. This experimental paradigm presents a visual display of two side-by-side faces producing a speech 
sound in synchrony with an auditory stimulus that conforms to only one of the faces. At test, infants are shown to exhibit longer looking times to the congruent auditory-visual stimulus, suggesting that infants can perceive correspondences between auditory and visual aspects of speech (Aldridge, Braga, Walton, \& Bower, 1999; Kuhl \& Meltzoff, 1982; MacKain, StuddertKennedy, Spieker, \& Stern, 1983; Patterson \& Werker, 1999; Pons, Lewkowicz, Soto-Faraco, \& Sebastián-Gallés, 2009). Infants' ability to perceive audio-visual congruence may be influenced by their concurrent ability to detect intersensory congruence in other domains; for example, many of the above authors report that infants make mouth movements or vocalisations that match those of the speakers in experimental trials (Kuhl \& Meltzoff, 1982; Kuhl \& Meltzoff, 1996; Legerstee, 1990; Patterson \& Werker, 1999, Coulon et al., 2013).

In order to examine the notion that motoric aspects of speech production play a role in infants' audio-visual matching ability, Yeung and Werker (2013) extend the scope of the above experimental paradigm. The researchers manipulate infants' oral-motor movements during the experimental trials and test their ability to perceive audio-visual congruence. In the experiment, 4.5-month-old infants are presented with two talking faces producing [i] and [u] in synchrony with an auditory stimulus of either [i] or [u]. Parents were instructed to hold either a finger or a teething toy in their infant's mouth to ensure that infants maintained the relevant articulatory configuration: either rounded lips or spread lips, respectively. Infants' were shown to prefer to attend to audiovisual incongruence when their lip movements had a similar configuration to those needed to produce the auditory stimulus. These looking time responses differed from those in a control condition, where infants produced the same lip shapes but heard an unrelated vowel sound, [a]. In this condition, infants failed to exhibit an attentional preference for either of the faces. These results provide evidence for the direct implication of sensorimotor information in audio-visual speech perception and suggest that infants recruit their articulatory knowledge about speech sounds to detect audio-visual congruence in their ambient language.

This interplay between infants' speech production abilities and their sensitivity to audio-visual congruence finds further support in Streri, Coulon, Marie, and Yeung's (2016) longitudinal study of infants' cross-modal transfer of sensorimotor information. Using parental reports of infants' individual developmental trajectories of vowel production at 3,6 and 9 months of age, the findings indicate that infants prefer to attend to incongruent audio-visual stimuli if the target vowel is inside their own production repertoire, and vice versa. This finding of an attentional preference for audiovisual incongruence accords with Altvater-Mackensen, Mani, and Grossman's (2016) similar investigation of whether infants' developmental trajectories of babble production influence their ability to detect audio-visual matches. The 6-month-old infants' task performance was shown to 
be related to their production abilities, and moreover, the data indicate that infants prefer to attend to audio-visual congruence if the relevant speech sound was outside their production repertoire, and vice versa. These two findings of an attentional preference for either familiarity or novelty according to an infant's individual speech production abilities thus parallel the developmental patterns in the studies on auditory-only speech perception reviewed above, where infants' preference to attend to specific speech sounds is modulated by the speech sounds in their own production repertoire (DePaolis et al., 2011; DePaolis et al., 2013; Majorano et al., 2014). Because these results show commonalities to those of auditory-only speech processing, the findings can likewise be accommodated within a Bayesian framework; infants' disposition to reduce prediction errors for audio-visual aspects of speech sounds within their repertoire may drive their motivation to seek out unexpected information in patterns of audio-visual incongruence.

Vilain, Dole, Lœvenbruck, Pascalis, and Schwartz (2019), moreover, explore how infants' sensitivity to audio-visual congruence for consonants relates to their individual production abilities. The authors test 6- and 9-month-old infants' ability to perceive audio-visual congruence by comparing their performance on consonantal stimuli within their production repertoire ([b] and [d]) and outside of their production repertoire ([v] and $[\mathrm{z}])$. Infants were shown to be able to perform intersensory matching only if the speech sounds were within their babbling repertoire, suggesting that the emergence of babbling may aid infants in their extraction of consonantal representations from the speech stream. The above studies suggest that infants' experience of producing a specific speech sound facilitates an understanding of its audio-visual concordance.

These studies provide robust evidence that infants can integrate information about speech sounds from auditory, visual, and sensorimotor modalities. Bayesian models of cognition offer a natural way to posit hypotheses about how information from these various sources lends probabilistic weight to different hypotheses; for example, both auditory and visual information may independently give probabilistic weight to a particular hypothesis about the speech sound, and information obtained from the most reliable sensory modality can be assigned the greatest amount of weight (Clark, 2013). Bayesian models thus place perception, action and cognition under the purview of a single set of computational principles and can provide a comprehensive construal of how domain-specific processing abilities interact over the course of infant development.

\section{0: Implications \& Directions for Future Research}

This paper employs a Bayesian approach to cognition in order to explore mechanistic commonalities in a variety of domains in the early stages of infant development. A systematic 
review of experiments on infants' ability to form predictions about probabilistic contingencies showed infants' behaviour to conform to the basic assumptions of a Bayesian model of cognition; infants show robust sensitivity to the probabilistic structure of their ambient environment and use their uncertainty about the world to forage for information. These same computational principles were shown to apply during language development; a systematic review of experiments on the relevance of infants' speech production to language development showed that infants explore and allocate attention to speech sounds that afford opportunities to reduce prediction error over time. This Bayesian explanation advances our understanding of the influence of infants' vocal exploration during language development and describes the interplay between familiarity and novelty with a single set of computational principles.

Because the cornerstone of a Bayesian framework revolves around iterative development, these models lend themselves well to describe the rapid changes observed in early infancy. In the face of new evidence, infants update the prior predictions of their internal model, and this adjusted model then functions as a new prior for making probabilistic inference (Clark, 2013; Hohwy, 2013). This simple construal of developmental change captures the notion that every sensory experience matters for change and contributes to the history of change (cf. Mareschal et al., 2007; Oakes \& Rakison, 2019; Thelen \& Smith, 1994). This unifying approach to learning highlights mechanistic commonalities among various aspects of infant development and advances our understanding of the nature of the processes that enable the emergence of complexity in infant cognition.

In order to acquire a better understanding of the implications of a Bayesian approach to developmental cognition, future research may further explore the extents and limits of these basic computational principles in early developmental stages. Most of the studies reviewed above employ violation-of-expectation responses as indirect measures of conceptual knowledge; however, because these behavioural measures depend on aggregating performance over many trials and participants, they prevent investigation of whether infants update their predictive models on a trial-to-trial basis. Future studies may benefit from a more fine-grained approach to studying infant development by using either neurophysiological or eye-tracking methods, which enable investigation of infants' individual trajectories of behavioural change on a trial-to-trial basis. The Bayesian framework offers explicit characterisation of such processes of rapid development and thus represents a structure of thought that can guide the formulation of theories required to investigate outstanding questions, such as how infants' intrinsic motivation to explore interacts with their resolve to reduce uncertainty about the world; how infants use prediction errors to update their predictive models; which computational algorithms best capture the mechanistic 
properties of infants' probabilistic sampling processes; how infants use their weighted confidence in actions to direct their exploration towards relevant aspects of the world; and how the formation and refinement of these predictive models manifest in the infant brain.

\section{0: Conclusion}

According to a Bayesian framework, infant learners develop through a process of model revision and recruit their own uncertainty to forage for relevant information in the world. As shown in the above analysis, a Bayesian approach to cognition provides a comprehensive framework that informs and explains insights from disparate fields of research on the early stages of cognitive development. This unifying framework emphasises mechanistic commonalities among various domains of infant cognition, such as probabilistic reasoning, social cognition, multimodal integration, motor development and language acquisition. This approach to cognitive development provides the conceptual tools to investigate the trial-by-trial updating of infants' knowledge and expectations and can serve as a useful framework to articulate explicit and testable hypotheses for future studies. These studies may focus on the nature of infants' internal representations of probabilistic structure and the algorithms infants use to sample information from their surrounding world. 


\section{0: List of References}

Aldridge, M. A., Braga, E. S., Walton, G. E., \& Bower, T. (1999). The intermodal representation of speech in newborns. Developmental Science, 2(1), 42-46.

Altvater-Mackensen, N., Mani, N., \& Grossmann, T. (2016). Audiovisual speech perception in infancy: The influence of vowel identity and infants' productive abilities on sensitivity to (mis)matches between auditory and visual speech cues. Dev Psychol, 52(2), 191-204. doi:10.1037/a0039964

Aslin, R. N. (2007). What's in a look? Developmental Science, 10(1), 48-53.

Aslin, R. N. (2012). Infant eyes: A window on cognitive development. Infancy, 17(1), 126-140.

Attisano, E., \& Denison, S. (2020). Infants' reasoning about samples generated by intentional versus non-intentional agents. Infancy, 25(1), 110-124.

Bonawitz, E., Denison, S., Griffiths, T. L., \& Gopnik, A. (2014). Probabilistic models, learning algorithms, and response variability: sampling in cognitive development. Trends in cognitive sciences, 18(10), 497-500.

Bruderer, A. G., Danielson, D. K., Kandhadai, P., \& Werker, J. F. (2015). Sensorimotor influences on speech perception in infancy. Proc Natl Acad Sci U S A, 112(44), 13531-13536. doi:10.1073/pnas.1508631112

Choi, D., Bruderer, A. G., \& Werker, J. F. (2019). Sensorimotor influences on speech perception In pre-babbling infants: Replication and extension of Bruderer et al. (2015). Psychon Bull Rev, 26(4), 1388-1399. doi:10.3758/s13423-019-01601-0

Clark, A. (2013). Whatever next? Predictive brains, situated agents, and the future of cognitive science. Behavioral and brain sciences, 36(3), 181-204.

Coulon, M., Hemimou, C., \& Streri, A. (2013). Effects of seeing and hearing vowels on neonatal facial imitation. Infancy, 18(5), 782-796.

de Bruin, L., \& Michael, J. (2018). Prediction error minimization as a framework for social cognition research. Erkenntnis, 1-20.

Denison, S., Reed, C., \& Xu, F. (2012). The emergence of probabilistic reasoning in very young infants: Evidence from 4.5-and 6-month-olds. Developmental psychology, 49(2), 243.

Denison, S., \& Xu, F. (2010a). Integrating physical constraints in statistical inference by 11-monthold infants. Cognitive science, 34(5), 885-908.

Denison, S., \& Xu, F. (2010b). Twelve-to 14-month-old infants can predict single-event probability with large set sizes. Developmental Science, 13(5), 798-803.

Denison, S., \& Xu, F. (2012). Probabilistic inference in human infants. In Advances in child development and behavior (Vol. 43, pp. 27-58): Elsevier. 
Denison, S., \& Xu, F. (2014). The origins of probabilistic inference in human infants. Cognition, 130(3), 335-347.

Denison, S., Trikutam, P., \& Xu, F. (2014). Probability versus representativeness in infancy: Can infants use naïve physics to adjust population base rates in probabilistic inference?. Developmental psychology, 50(8), 2009-2019.

DePaolis, R. A., Vihman, M. M., \& Keren-Portnoy, T. (2011). Do production patterns influence the processing of speech in prelinguistic infants? Infant Behavior and Development, 34(4), $590-601$.

DePaolis, R. A., Vihman, M. M., \& Nakai, S. (2013). The influence of babbling patterns on the processing of speech. Infant Behavior and Development, 36(4), 642-649.

Emberson, L. L., Richards, J. E., \& Aslin, R. N. (2015). Top-down modulation in the infant brain: Learning-induced expectations rapidly affect the sensory cortex at 6 months. Proceedings of the National Academy of Sciences, 112(31), 9585-9590.

Feldman, H., \& Friston, K. (2010). Attention, uncertainty, and free-energy. Frontiers in Human Neuroscience, 4, 215.

FeldmanHall, O., \& Shenhav, A. (2019). Resolving uncertainty in a social world. Nature buman behaviour, 3(5), 426-435.

Friston, K. (2005). A theory of cortical responses. Philosophical transactions of the Royal Society B: Biological sciences, 360(1456), 815-836.

Friston, K. (2009). The free-energy principle: a rough guide to the brain? Trends in cognitive sciences, 13(7), 293-301.

Friston, K. (2010). The free-energy principle: a unified brain theory? Nature Reviews Neuroscience, 11(2), 127-138.

Gopnik, A., O’Grady, S., Lucas, C. G., Griffiths, T. L., Wente, A., Bridgers, S., ... \& Dahl, R. E. (2017). Changes in cognitive flexibility and hypothesis search across human life history from childhood to adolescence to adulthood. Proceedings of the National Academy of Sciences, 114(30), 7892-7899.

Gweon, H., Tenenbaum, J. B., \& Schulz, L. E. (2010). Infants consider both the sample and the sampling process in inductive generalization. PNAS Proceedings of the National Academy of Sciences of the United States of America, 107(20), 9066-9071. doi:http://dx.doi.org/10.1073/pnas.1003095107

Hohwy, J. (2013). The predictive mind: Oxford University Press.

Kanai, R., Komura, Y., Shipp, S., \& Friston, K. (2015). Cerebral hierarchies: predictive processing, precision and the pulvinar. Philosophical transactions of the Royal Society B: Biological sciences, 
370(1668), 20140169.

Kanakogi, Y., \& Itakura, S. (2011). Developmental correspondence between action prediction and motor ability in early infancy. Nature communications, 2(1), 1-6.

Kayhan, E., Gredebäck, G., \& Lindskog, M. (2018). Infants distinguish between two events based on their relative likelihood. Child Development, 89(6), e507-e519.

Kayhan, E., Hunnius, S., O'Reilly, J., \& Bekkering, H. (2019). Infants differentially update their internal models of a dynamic environment. Cognition, 186, 139-146.

Kidd, C., Piantadosi, S. T., \& Aslin, R. N. (2012). The Goldilocks effect: Human infants allocate attention to visual sequences that are neither too simple nor too complex. PloS one, 7(5), e36399.

Kim, S., Sodian, B., \& Proust, J. (2020). 12-and 24-Month-Old Infants' Search Behavior Under Informational Uncertainty. Frontiers in psychology, 11, 566.

Kouider, S., Long, B., Le Stanc, L., Charron, S., Fievet, A. C., Barbosa, L. S., \& Gelskov, S. V. (2015). Neural dynamics of prediction and surprise in infants. Nat Commun, 6, 8537. doi:10.1038/ncomms9537

Kuhl, P., \& Meltzoff, A. (1982). The bimodal perception of speech in infancy. Science, 218(4577), 1138-1141.

Kuhl, P. K., \& Meltzoff, A. N. (1982). Bimodal speech perception in early infancy. The Journal of the Acoustical Society of America, 71(S1), S77-S78.

Kuhl, P. K., \& Meltzoff, A. N. (1996). Infant vocalizations in response to speech: vocal imitation and developmental change. J Acoust Soc Am, 100(4 Pt 1), 2425-2438. doi:10.1121/1.417951

Legerstee, M. (1990). Infants use multimodal information to imitate speech sounds. Infant Behavior and Development, 13(3), 343-354.

Lucas, C. G., Bridgers, S., Griffiths, T. L., \& Gopnik, A. (2014). When children are better (or at least more open-minded) learners than adults: Developmental differences in learning the forms of causal relationships. Cognition, 131(2), 284-299.

MacKain, K., Studdert-Kennedy, M., Spieker, S., \& Stern, D. (1983). Infant intermodal speech perception is a left-hemisphere function. Science, 219(4590), 1347-1349.

Majorano, M., Vihman, M. M., \& DePaolis, R. A. (2014). The relationship between infants' production experience and their processing of speech. Language Learning and Development, 10(2), 179-204.

Mareschal, D., Johnson, M. H., Sirois, S., Thomas, M. S., Spratling, M., Spratling, M. W., \& Westermann, G. (2007). Neuroconstructivism: How the brain constructs cognition. Oxford University Press. 
McCune, L., \& Vihman, M. M. (2001). Early phonetic and lexical development. Journal of Speech, Language, and Hearing Research 44, 670-684.

Oakes, L. M., \& Rakison, D. H. (2019). Developmental cascades: Building the infant mind. Oxford University Press.

Patterson, M. L., \& Werker, J. F. (1999). Matching phonetic information in lips and voice is robust in 4.5-month-old infants. Infant Behavior and Development, 22(2), 237-247.

Placì, S., Fischer, J., \& rakoczy, h. (2019). Do infants and preschoolers quantify probabilities based on proportions?. https://doi.org/10.31234/osf.io/u8ect

Pons, F., Lewkowicz, D. J., Soto-Faraco, S., \& Sebastián-Gallés, N. (2009). Narrowing of intersensory speech perception in infancy. Proceedings of the National Academy of Sciences, 106(26), 10598-10602.

Rovee-Collier, C. (1997). Dissociations in infant memory: Rethinking the development of implicit and explicit memory. Psychological Review, 104(3), 467-498.

Sommerville, J. A., Woodward, A. L., \& Needham, A. (2005). Action experience alters 3-monthold infants' perception of others' actions. Cognition, 96(1), B1-B11.

Stahl, A. E., \& Feigenson, L. (2015). Observing the unexpected enhances infants' learning and exploration. Science, 348(6230), 91-94.

Streri, A., Coulon, M., Marie, J., \& Yeung, H. H. (2016). Developmental change in infants' detection of visual faces that match auditory vowels. Infancy, 21(2), 177-198.

Téglás, E., Girotto, V., Gonzalez, M., \& Bonatti, L. L. (2007). Intuitions of probabilities shape expectations about the future at 12 months and beyond. Proceedings of the National Academy of Sciences, 104(48), 19156-19159.

Téglás, E., Ibanez-Lillo, A., Costa, A., \& Bonatti, L. L. (2015). Numerical representations and intuitions of probabilities at 12 months. Developmental Science, 18(2), 183-193.

Téglás, E., Vul, E., Girotto, V., Gonzalez, M., Tenenbaum, J. B., \& Bonatti, L. L. (2011). Pure reasoning in 12-month-old infants as probabilistic inference. Science, 332(6033), 1054-1059.

Thelen, E., \& Smith, L. B. (1994). A dynamic systems approach to the development of cognition and action: The MIT Press, Cambridge, MA.

Twomey, K. E., \& Westermann, G. (2018). Curiosity-based learning in infants: a neurocomputational approach. Developmental science, 21(4), e12629.

Vilain, A., Dole, M., Lœvenbruck, H., Pascalis, O., \& Schwartz, J. L. (2019). The role of production abilities in the perception of consonant category in infants. Dev Sci, 22(6), e12830. doi:10.1111/desc.12830

Wellman, H. M., Kushnir, T., Xu, F., \& Brink, K. A. (2016). Infants use statistical sampling to 
understand the psychological world. Infancy, 21(5), 668-676.

Xu, F., \& Denison, S. (2009). Statistical inference and sensitivity to sampling in 11-month-old infants. Cognition, 112(1), 97-104.

Xu, F., \& Garcia, V. (2008). Intuitive statistics by 8-month-old infants. Proceedings of the National Academy of Sciences, 105(13), 5012-5015.

Yeung, H. H., \& Werker, J. F. (2013). Lip movements affect infants' audiovisual speech perception. Psychol Sci, 24(5), 603-612. doi:10.1177/0956797612458802 